\title{
LIST OF ABSTRACTS
}

\section{Management Accounting Innovations in Italian compa- nies: a comparative research (Lino Cinquini, Paolo Collini, Alessandro Marelli, Andrea Tenucci)}

\begin{abstract}
An interest in new management accounting techniques has driven the attention of surveys to the technical or theoretical aspects of the new costing models proposed. However, the nonlinear process of the diffusion of innovative techniques as a consequence of the learning process and "fashion effect" has received limited attention in survey-based research.

This paper compares the results of two surveys conducted ten years part on a sample of companies located in Italy. The comparison covers a broad range of issues concerning cost information purposes, cost allocation and the implementation of two specific advanced costing techniques (Activity-Based Costing and Target Costing). The paper provides insights for the "accounting change" research agenda in two directions: one concerning demand-side versus supply-side arguments about the accounting change (Ax and Bjørnenak, 2007) and the other on the non-linearity and unsystematic process of accounting change over a long period of time (Burns and Vaivio, 2001).
\end{abstract}

Keywords: Management accounting innovations, Activity-Based Costing, Target Costing, Product Costing Design, Accounting change research

\section{Systems and Measures of Business Performances: Lit- erature Review and Research Streams (Nicola Castellano)}

\begin{abstract}
Performance Measurement Systems (PMS) are designed and implemented with the purpose to guide the behavior of managers towards the achievement of company strategies. Moreover the employment of these tools is strengthen in the light of the limitations of traditional management control tools which give an excessive emphasis to financial measures thus hindering an effective comprehension of either the results obtained, or the related management drivers, or the consequent selection of management improving actions.
\end{abstract}


This paper tries to analyze the most recent international literature on PMS with the purpose to underline the most discussed topics, the most employed research methodologies and the most significant findings. Following previous theoretical contribution, the papers selected have been classified considering the basic life cycle phases of PMS: design, implementation and usage. In the final section are proposed further research development streams.

Keywords: Performance Measurement Systems, Performance Measures, Balanced Scorecard, Research Methods

\title{
Business Networks and Strategic Alliances. Role of Relational Information Systems (Daniela Mancini)
}

\begin{abstract}
In recent years, cross-company relationships, strategic alliances and complex business networks are increasingly a typical way used by companies to grow and an important component of corporate strategy. As a result, the horizon within which the assessment of economic convenience and the decision making take place is enlarged beyond the boundaries of each company.

The object of this article is to highlight some open problems in the study of information systems of a firm that based its business on a number of different strategic alliances into different networks (the enterprise-network). According to the author, for this enterprise the information management is a key factor for the success of relationships developed across-boundaries. On the one hand, the information system becomes a key element aligning the processes of governance and control of the network of relationships. On the other side, strategic alliances act as an important factor of change for the enterprise information system that needs to be investigated in its different component. This article is divided into two parts. In the first two paragraphs the author describes the multidimensional relationship between the governance system, control system and information system in relational contexts. In the following paragraphs the focus is on relational information system.
\end{abstract}

Keywords: business networks, strategic alliances, relational information system, relational governance, relational control

\section{Customer-oriented control tools: a systemic analysis (Marco Gatti)}

Abstract: In recent times control tools have seen a significant renewal. The development of new tools aimed at controlling some critical aspects of customer rela- 
tions has attracted scholars' attention; this has led to a focus on the distinctive features and use of these control tools. The purpose of this article is, in general terms, to illustrate how the multidimensional information produced by the tools analyzed may be used in an integrated manner within the control system and, in particular, to highlight the ways in which it can be employed to support the calculation of customer lifetime value.

Keywords: customer-oriented control, customer lifetime value, integration of multidimensional information

\title{
Disclosure on the internal control system as a monitoring mechanism: evidence from different institutional settings (Saverio Bozzolan)
}

\begin{abstract}
The study addresses the issue of disclosure on Internal Control System (ICS) in the light of the agency theory. The autors posit that reporting to investors on the characteristics of ICS is an alternative governance mechanism that management enacts when other devices are not effective. Analyzing the disclosure on ICS of 160 European firms listed in four different stock exchanges (London, Paris, Frankfurt and Milan) over a three-year period (2003-2005), the autors found empirical evidence that ICS disclosure is a substitute for the monitoring role played by the ownership structure, institutional ownership, the proportion of independent directors sitting on the board and the proportion of accounting expert members of the audit committee. This study provides empirical support for Williamson's (1983) substitute hypothesis among different governance mechanisms. This study offers insights to firms and practitioners on the relevance of making disclosure on ICS as a monitoring mechanism for investors.
\end{abstract}

Keywords: Corporate governance, Monitoring package, Internal control systems, Disclosure, Ownership structure, Board of directors, Audit committee

\section{Corporate governance, risk management and corporate social responsibility: current roles and future trends for internal auditing activities (Marco Allegrini, Giuseppe D’Onza)}

Abstract: This article aims to analyze the activities performed by the internal auditing department (IAD) and the expected trends for the forthcoming future. The existing literature highlights that many IADs are currently playing a key role for 
List of abstracts

improving the effectiveness of corporate governance, risk management and CSR projects.

This article is based on the results of two international surveys and provides an answer to the following research questions: - to what extent and which activities the IAD are currently performing in the area of corporate governance, risk management and CSR?; - are there significant differences between: the 2006 and the 2010?; the "developed" and the "new industrialized" regions?; industries?

The overall results show that in the 2010 the percentage of IA activities that refer to risk management is higher than for corporate governance and CSR. Respondents expect that the role of the IAD in risk management and corporate governance will continue to increase in the next five years. However the trends for the future are not uniform between regions and industries: these two activities are expected to increase more in "new industrialized" regions, in financial services industry and in raw material and agriculture industry.

Keywords: internal auditing, corporate governance, risk management, corporate social responsibilities 